\title{
Negative impacts of gambling on Asian families and communities in New Zealand
}

\author{
Amritha Sobrun-Maharaj ${ }^{1 *}$, Fiona V Rossen ${ }^{2}$ and Anita S K Wong ${ }^{1}$
}

\author{
* Correspondence: sobrun- \\ maharaj@auckland.ac.nz \\ ${ }^{1}$ Centre for Asian and Ethnic \\ Minority Health Research, School of \\ Population Health, University of \\ Auckland, 261 Morrin Road, Glen \\ Innes, Auckland 1072, New Zealand \\ Full list of author information is \\ available at the end of the article
}

\begin{abstract}
This paper outlines a project that investigated the impact of gambling and problem gambling on the health and wellbeing of Asian families and communities in New Zealand. This 2-year, multi-phase qualitative project included focus group discussions and individual face-to-face interviews with stakeholders and individuals who have experienced or been impacted by problem gambling across New Zealand's five major Asian ethnic subgroups of Chinese, Indian, Korean, Southeast Asian and Asian with Refugee background. This paper provides details on two major themes that emerged from the data: the role of settlement, the environment and coping behaviours in problem gambling amongst Asians; and, the impacts and consequences of gambling for Asian people and their families. Problem gamblers were found to employ dysfunctional coping strategies to deal with settlement adversities with adverse effects on the mental health and social and financial wellbeing of individuals, families and communities. Based on the data provided by participants, potential strategies have been developed for enhancing resilience through other variables that protect against problem gambling, and moderating those variables that may increase risk for problem gambling. These include: utilising cultural strengths, building trust, normalising help-seeking, educating Asian communities about the dangers of gambling, and creating a supportive social and institutional environment for Asian immigrants.
\end{abstract}

\section{Background}

Asians make up the fastest-growing ethnic community in New Zealand today. According to the 2006 census statistics, Asians made up the fourth largest major ethnic group after European, Māori and Other Ethnicity, totalling 354,552 people (9.2\%) in 2006. Chinese, Indians and Koreans are the three major contributors in the increasing trend of the Asian population. Many are born overseas (30-40\%) and some (15\%) do not speak English (Statistics New Zealand 2010). This growing Asian population (ibid.) has emerging health issues that need attention to ensure that they do not exacerbate and become a burden to the Asian community and the New Zealand health system (Ministry of Health 2006; Parackal et al. 2011; Scragg 2010).

The literature on acculturation illustrates the high levels of stress that immigrants experience when settling into a new country. This experience of cross-cultural stress is known as culture shock (Furnham \& Bochner 1986) and can be particularly intense throughout the early stages of immigration (McIntyre 2008 [Ethnic minority migrant Chinese in New Zealand: A study into their acculturation and workplace interpersonal 
conflict experiences, Unpublished $\mathrm{PhD}]$ ). Early research shows that immigrants first need to go through a process of 'de-culturation' in order to acculturate to their new country (Bar-Yosef 1968; Eisenstadt 1954). De-culturation involves unlearning some of the immigrants' childhood cultural patterns and other beliefs and behaviours. This in itself may evoke stress and anxiety, and together with the acculturation experience, often results in mental health issues (McIntyre 2008 [Ethnic minority migrant Chinese in New Zealand: A study into their acculturation and workplace interpersonal conflict experiences, Unpublished $\mathrm{PhD}]$ ).

An emerging mental health issue identified for Asians in New Zealand is problem gambling. Gambling often provides individuals with a certain amount of relief or escape from problems occurring in their life (Abbott \& Volberg 2000; Blaszczynski \& McConaghy 1989) and can offer a temporary but effective reprieve from painful personal realities (Tavares et al. 2003; Welte et al. 2004; Wong \& Tse 2003). Moreover, research has found that gambling whilst experiencing negative mood states, increases the likelihood of continued gambling regardless of repeated losses. This is the case even for non-problematic gamblers (Raghunathan \& Pham 1999).

The disproportionate impacts of problem gambling amongst Asian communities have been highlighted elsewhere. Internationally, anecdotal accounts, media reports and recent research studies have made reference to the increasing level of participation in gambling by people from Asian countries (Blaszczynski et al. 1998; Chinese Family Life Services of Metro Toronto 1995; Cultural Partners Australia Consortium 2000; Petry et al. 2003). For instance in Australia, it was found that members of the Chinese community were almost 50 percent more at risk of developing problem gambling compared with their Caucasian counterparts (Raylu \& Oei, 2004). Asian people from a refugee background (Marshall et al. 2009; Petry et al. 2003) and international students (e.g. Gambling Research Australia 2011) have been found to be particularly at risk of problem gambling.

There is a limited body of research dedicated to Asian gambling issues in New Zealand and little is known about the impacts of gambling on Asian immigrant families and communities in New Zealand. There is a clear need for accurate knowledge of these issues. This study was undertaken in response to this need with a view to filling the gap in this knowledge. It investigated the role of migration, settlement and the environment in gambling and problem gambling amongst Asian immigrants. It also explored and attempted to improve understanding of the coping behaviours, impacts and consequences of gambling and problem gambling for Asian immigrants and their families.

This paper provides details on two major themes that emerged from the data: 1) the role of settlement, the environment and coping behaviours in problem gambling amongst Asians, 2) the impacts and consequences of gambling for Asian people and their families.

\section{Methods}

The study adopted an ecological approach to exploring the impacts of gambling and problem gambling on the health and wellbeing of Asian immigrant families and communities within New Zealand, and utilised ecological and acculturation frameworks to assist with the analysis and interpretation of gambling-related experiences. An ecological approach 
(Bronfenbrenner, 1979; Swick \& Williams, 2006; Berk, 2000; Addison, 1992) values and acknowledges the contextual framework in which individuals live and operate. It allows consideration of the multiple environments in which individuals operate and the complex roles/relationships that they fulfil within these environments. Acculturation is broadly defined as "those phenomena which result when groups of individuals having different cultures come into continuous first-hand contact, with subsequent changes in the original cultural patterns of either or both groups" (Salant \& Lauderdale, 2003, p. 72). An acculturation framework posits that highly variable cultural and psychological outcomes follow from intergroup contact. Berry (2005) argues that two key issues intersect to determine acculturation outcomes: the desire to maintain cultural heritage and identity and the level of relationship sought among groups. The resulting intersection of these issues can be categorised into four acculturation strategies that are employed by ethno-cultural groups: integration, separation, assimilation and marginalization (Berry 2005). Studies with Asian immigrants in New Zealand (e.g., Sobrun-Maharaj et al. 2009; Tse et al. 2006) suggest that these communities may be employing different acculturation strategies with some continuing to experience high degrees of marginalisation, which may erode the levels of resilience that they bring with them, with mental health consequences.

Through a mixed methods qualitative design, data were gathered in four phases: Review of literature; Focus group discussions; Individual interviews; and Stakeholder group discussions. Sixteen focus group discussions were conducted with stakeholders from each of the four major Asian ethnic subgroups in New Zealand, i.e. Chinese, Indian, Korean and Southeast Asian, and with Asians from a refugee background; 50 face-to-face interviews were then completed with individuals across the five groups; finally, four focus group discussions were conducted with stakeholders in New Zealand's four major cities: Auckland, Hamilton, Wellington, and Christchurch.

Participants were recruited from diverse backgrounds and with varying gamblingrelated experiences, through researchers' professional, community and personal networks and through the use of flyers and snowballing techniques. Consideration was given to factors such as: age, gender, country of birth, English language proficiency, length of residency in New Zealand, occupation, family composition, and level of engagement / relationship with gambling (i.e. social gambler, problem gambler, significant other). Tables 1 and 2 provide demographic data of participants.

A preliminary focus group discussion with problem gambling intervention staff and other key stakeholders aimed to explore and identify the key issues relating to gambling for Asian families and communities in New Zealand. The findings from this discussion were used to inform and establish a question guide for use in focus group discussions and individual interviews that were conducted by experienced focus group facilitators and interviewers who were ethnically matched to the participants. Key topic areas included:

- Cultural assumptions about gambling and problem gambling (focus group only);

- Background in gambling (individual interviews only);

- Individual, familial and community impacts associated with gambling;

- Risk and resiliency factors in relation to Asian gambling;

- Help-seeking behaviour; and,

- Other issues. 
Table 1 Break-down of focus group participants by ethnicity, age, gender and years in New Zealand

\begin{tabular}{|c|c|c|c|c|c|c|}
\hline \multicolumn{7}{|c|}{ ETHNICITY } \\
\hline & $\begin{array}{l}\text { Korean } \\
(n=10)\end{array}$ & $\begin{array}{l}\text { Chinese } \\
(n=10)\end{array}$ & $\begin{array}{l}\text { South Asian } \\
(n=10)\end{array}$ & $\begin{array}{l}\text { S-East Asian } \\
\quad(n=10)\end{array}$ & $\begin{array}{l}\text { Refugee } \\
(n=10)\end{array}$ & $\begin{array}{l}\text { TOTAL* } \\
(n=50)\end{array}$ \\
\hline \multicolumn{7}{|l|}{ Age } \\
\hline $20-29$ & 2 & 2 & 6 & 1 & 0 & 11 \\
\hline $30-39$ & 1 & 2 & 3 & 4 & 2 & 12 \\
\hline $40-49$ & 5 & 2 & 0 & 3 & 5 & 15 \\
\hline $50-59$ & 2 & 4 & 1 & 2 & 2 & 11 \\
\hline $60+$ & 0 & 0 & 0 & 0 & 1 & 1 \\
\hline \multicolumn{7}{|l|}{ Gender } \\
\hline Male & 5 & 5 & 7 & 3 & 6 & 26 \\
\hline Female & 5 & 5 & 3 & 7 & 4 & 24 \\
\hline \multicolumn{7}{|c|}{ Years in NZ } \\
\hline$<1$ year & 0 & 0 & 1 & 0 & 0 & 1 \\
\hline 1 to 4 & 0 & 0 & 4 & 0 & 0 & 4 \\
\hline 5 to 9 & 4 & 0 & 2 & 2 & 2 & 10 \\
\hline 10 to 19 & 6 & 3 & 3 & 6 & 4 & 22 \\
\hline $20+$ & 0 & 4 & 0 & 2 & 3 & 9 \\
\hline $30+$ & 0 & 3 & 0 & 0 & 1 & 4 \\
\hline
\end{tabular}

* NB: As completion of the participant demographic form (administered at the beginning of each individual interview) was not compulsory, the sum of row totals may not equate to the total number of participants in each ethnic stream.

Table 2 Break-down of face-to-face interview participants by ethnicity, age, gender and years in New Zealand

\begin{tabular}{|c|c|c|c|c|c|c|}
\hline \multicolumn{7}{|c|}{ ETHNICITY } \\
\hline & $\begin{array}{l}\text { Korean } \\
(n=24)\end{array}$ & $\begin{array}{l}\text { Chinese } \\
(n=23)\end{array}$ & $\begin{array}{l}\text { South Asian } \\
(n=17)\end{array}$ & $\begin{array}{l}\text { S-East Asian } \\
(n=23)\end{array}$ & $\begin{array}{c}\text { Refugee } \\
(n=7)\end{array}$ & $\begin{array}{l}\text { TOTAL* } \\
(n=94)\end{array}$ \\
\hline \multicolumn{7}{|l|}{ Age } \\
\hline $20-29$ & 1 & 1 & 6 & 2 & 2 & 12 \\
\hline $30-39$ & 3 & 6 & 4 & 4 & 2 & 19 \\
\hline $40-49$ & 2 & 9 & 1 & 7 & 2 & 21 \\
\hline $50-59$ & 2 & 5 & 1 & 6 & 1 & 15 \\
\hline $60+$ & 1 & 2 & 5 & 3 & 0 & 11 \\
\hline \multicolumn{7}{|l|}{ Gender } \\
\hline Male & 5 & 9 & 8 & 10 & 4 & 36 \\
\hline Female & 4 & 14 & 9 & 13 & 3 & 43 \\
\hline \multicolumn{7}{|c|}{ Years in NZ } \\
\hline$<1$ year & 0 & 0 & 3 & 1 & 0 & 4 \\
\hline 1 to 4 & 3 & 2 & 8 & 2 & 1 & 16 \\
\hline 5 to 9 & 2 & 5 & 1 & 2 & 3 & 13 \\
\hline 10 to 19 & 4 & 11 & 5 & 5 & 3 & 28 \\
\hline $20+$ & 0 & 2 & 0 & 9 & 0 & 11 \\
\hline $30+$ & 0 & 0 & 0 & 1 & 0 & 1 \\
\hline
\end{tabular}

* NB: As completion of the participant demographic form (administered at the beginning of each focus group) was not compulsory, the sum of row totals may not equate to the total number of participants in each ethnic stream. 
A general inductive approach (Thomas 2006) was used to analyse the qualitative data, enabling the identification of themes, clusters and categories. The research team ensured methodological rigour by allowing for a 'consistency check' on the analysis by conducting a parallel process of independent analysis of the data and determining key themes by consensus (Patton 1990).

The University of Auckland Human Participants Ethics Committee (UAHPEC) approved the study. A cultural advisory group provided expert cultural advice and guidance on issues such as data collection measures and procedures, commented on preliminary findings and aided with the interpretation and contextualisation of the resulting data.

\section{Results and discussion}

The findings from this study suggest that the migration and settlement experience may be an important antecedent of gambling and problem gambling for many Asian immigrants and refugees. Acculturation and settlement stress caused by cultural differences, financial difficulties and concomitant family stress; negative environmental factors such as social isolation and gambling culture, and the impact this has on their ability to cope with adversities, were all found to contribute to this.

Findings are categorised into two themes. The first focuses on the issues raised by participants in relation to migration, settlement and the environment: acculturation and settlement stress, social environment factors, and coping strategies. The second relates to the negative impacts and consequences associated with problem gambling for Asian immigrants and their families, on which participants overwhelmingly focussed.

\section{Acculturation and settlement stress}

Cultural and language differences, financial stress and family stress were cited as the most important causes of acculturation and settlement stress.

Cultural and language differences and subsequent difficulties with social interaction and integration into mainstream New Zealand society encouraged Asian immigrants and refugees to socialise with people from their own ethnic communities. Participants indicated that a convenient and safe venue for socialisation was the casino where language is not an impediment and various other facilities are easily available.

"There is a huge culture difference ... for migrants, like I don't watch sports etc., watching sports is such a kiwi culture. So when Chinese meet the Chinese, there is familiarity and naturally they form their own cultural groups at the casino."

However, they recognised that socialising in the casino exposes an already vulnerable group to gambling and potential gambling related problems:

"I believe migrants are at least twice more vulnerable to gambling addiction than local people. They have stressful things to deal with that local people won't have, like language, new culture, unfamiliarity and so on... They need special care. The casino should not be a substitute."

Financial stress emerged as a major cause of gambling amongst many immigrant and refugee families. Despite the stigma attached to gambling, some were reported to 
sanction it because it could relieve the financial stress they experience as a result of settlement difficulties:

"Financial stress is the major problem. Some wives react differently if their husband says 'today I put $\$ 300$ in gambling but won $\$ 10,000$ or $\$ 100,000$ '. Even if they see it as a stigma on their status, she might encourage her husband to gamble."

The casino is seen as a place that provides the opportunity to relieve financial stress:

"I was desperate to earn some money to live. After about 4 to 5 months, I followed other staff to the casino. I used $\$ 20$ to get hundreds of dollars in return... That's how I started going to the casino almost every day."

The major source of financial stress for immigrants and refugees is inadequate employment or unemployment. This was reported as a major contributor to gambling activity:

"Employment is the biggest risk factor that promotes gambling amongst immigrants... it's very hard for immigrants to find a job."

This corresponds with national (Chang et al. 2006; Henderson et al. 2001; Sobrun-Maharaj et al. 2011) and international literature (e.g., Aycan \& Berry, 1996; Beiser \& Hou 2001; Bell et al. 2004) which show that financial stress is a major issue for Asian and other ethnic minority immigrants and refugees and that this has important mental health impacts.

An underlying value of the collectivistic Asian culture is the shared responsibility for the wellbeing of others in their family and community. Participants reported that family responsibilities, including sending remittances home, could act as risk factors if gambling is seen as a solution to financial problems:

"I needed money to support my children living in Lao, which caused me to gamble."

"He is always thinking about how to make money from the casino. They always have pressure from the family... to stabilise family expenses, to pay money to others..."

On the other hand, for some, having a family for whom you are responsible can also act as a protective factor against gambling and a motivator to address problem gambling as it can reduce levels of disposable time, money, and the inclination to gamble:

"I have no time and interest to gamble anymore, I need to work and look after my children. If I continued gambling, I would not able to save money to sponsor my children, and finally, they would not be able to come to New Zealand."

"He has to send lots of money to family members back home, so that makes him not gamble."

The settlement and acculturation process often results in substantial stress within families. This can be partly attributed to the changes in roles and dynamics, especially the power structure within Asian families, which occur within families adapting to a new culture. The employment challenges experienced by most Asians settling into New Zealand often results in female spouses entering the workforce sooner than males as they may be 
willing to take on less prestigious or appropriate jobs to support the family while their husbands look for the "right" job (Sobrun-Maharaj et al. 2011). This empowers women and displaces the male's primary position and disrupts the hierarchy within the family, often resulting in inter-spousal conflict and consequent anxiety, depression and other mental health issues. In some cases, the empowerment of women in their western host country with a more liberal set of values has led to women engaging in gambling:

"I gambled to show my husband that I can make money too, because he didn't allow me to have money. In our culture, women used to stay at home, manage the family money, and look after the children..."

As evidenced in this quotation, this role reversal and conflict sometimes places family members at risk for addictive behaviours such as gambling. For Asian men in particular, who are accustomed to being dominant within their families, a loss of power and self-esteem was often perceived by participants as leading to behaviours such as problem gambling. This was reportedly exacerbated by intergenerational conflict arising from children acculturating faster than adults:

"When he goes out to gamble, it is often after having arguments or troubles with children at home. Then he shouts and goes out. It seems like it provokes it..."

Intergenerational conflict also has consequences for children who sometimes engage in addictive behaviour such as drug and alcohol abuse and gambling:

"We don't have control of our children as much as we used to have in India... Some kids listen, some don't. They go for all bad habits like drinking, partying, drug use. And then gambling is just a next step."

Intergenerational cultural dissonance (ICD) or conflict has been reported in other studies to be a major problem arising from acculturation with a variety of negative consequences for Asian families and children (e.g. Chung 2001; Kibria 1993; Lee et al. 2005; Ying et al. 1999).

\section{Social environment factors}

Apart from the stresses discussed above, a sense of isolation, disempowerment and hopelessness in the new social environment has a major impact on the ability of immigrants and refugees to settle into their adopted country, as shown by national and international studies (e.g., Dyal \& Dyal 1981; McIntyre 2008 [Ethnic minority migrant Chinese in New Zealand: A study into their acculturation and workplace interpersonal conflict experiences, Unpublished PhD]; Yeh 2003).

Social isolation was cited as a major issue for Asians engaged in gambling behaviours. Participants indicated that they had become susceptible to gambling as a consequence of their settlement difficulties and experiences of isolation:

"I feel very disempowered here. There is not much I can do... I began to go to the casino as I felt like there is no purpose in my life. I could focus on playing pokie machines when I was at the casino." 
Three key factors relating to social isolation were raised by participants: lack of social and family support; lack of acceptance by the host population; and lack of entertainment. Lack of acceptance of Asians in New Zealand is widely acknowledged and has been raised in other studies undertaken with Asians (e.g., 3 News 2009; New Zealand Press Association (NZPA) 2008; Sobrun-Maharaj et al., 2009; Ward \& Masgoret 2007). Not having family or friends to interact with encouraged people to find companionship in the casino; a strategy that was widely reported by gamblers and family members across most of the ethnic groups:

"I don't have many friends and family members here. So I don't have much to do and am usually on my own. If you go to the casino, there are people and many Asians everywhere and I feel better."

A major issue, and one that contributes to loneliness and isolation for immigrants, is the lack of entertainment in New Zealand. The casino is the only place that offers entertainment in a safe environment throughout the night:

"In NZ there are no night shopping malls and markets like Asia and people who speak your language... NZ is too boring... so gambling is another activity to do and plus, there is excitement."

"There are not many places where Asian women can go at night. You don't want to sit surrounded by all western people in a foreign bar at night. But at Casino, there are lots of Asians so it makes me feel comfortable. No one would bother you. Also there are cameras everywhere. It makes me feel safe to be in there as an Asian woman."

Participants perceived New Zealand's legal gambling culture and ease of accessibility of gambling to encourage Asians to engage in gambling. Furthermore, they reported that Asian immigrants are confronted with comprehensive marketing campaigns which glamorise and normalise gambling in New Zealand. The accessibility of gambling, particularly those activities associated with high risk, when coupled with the perception that the legality of gambling means that it is harmless, provides Asian immigrants with a confusing picture. Participants expressed confusion about the government allowing activities that can be harmful to people. They assume that the government would have the wellbeing of their people at heart and would not expose them to danger:

"I can't understand how gambling is legal and so easy to access here... How come the government lets the business prosper?...You go to the Casino and look at who they are; they are all Asians... They go to the Casino to get rid of stress. The Casino is very good at exploiting it, and the government allows it."

The extent to which negative aspects of their settlement experience and the social environment impact upon the resilience that Asian immigrants and refugees bring with them will determine how they cope with these stresses in New Zealand and the extent to which they are at risk of problem gambling. Studies have found a correlation between perceptions of rejection, bad health and low self-esteem and that there is 
reciprocity between low self-esteem and coping (Leary 1990; Rigby 1996; SobrunMaharaj 2002). People with lowered self-esteem are likely to be less resilient and to employ dysfunctional methods of coping such as resorting to addictive behaviours.

\section{Coping strategies employed by Asian immigrants}

The international literature on coping shows that the strategies utilised by people to cope with stress predict levels of subsequent stress and crisis in their lives (Ivie \& Garland 2011), and that some employ functional or problem-solving strategies and others employ dysfunctional or avoidant strategies. New Zealand studies (e.g. Dixon et al., 2010) show that some Asians are able to cope with settlement adversities functionally, while others employ dysfunctional coping strategies with adverse effects on mental health and wellbeing. Functional coping strategies, such as self-control, seeking social support, accepting responsibility, planful problem solving and positive reappraisal (Folkman \& Lazarus, 1988) enable the avoidance of behaviours such as problematic gambling. Conversely, dysfunctional coping such as escape-avoidance, distancing, and confrontational coping (ibid.), which reflect an inability to cope functionally, may result in greater psychological and physical problems (Sprinthall \& Collins 1995), and have been linked with negative mental health outcomes such as anxiety, somatic problems, and depression (Endler \& Parker 1990). It increases the risk of issues such as problem gambling and the subsequent negative impacts and consequences for families and communities.

The data from this research revealed that some participants employed functional coping strategies for migration and settlement issues, including recognising and acknowledging gambling-related problems, taking action to address difficulties, and engaging with spirituality and religion. These strategies appeared to protect against problem gambling and may have been facilitated by higher levels of resilience. However, many Asian gamblers and families evidently employed dysfunctional coping strategies in response to these problems, which may have been impacted by lower levels of resilience. Strategies included, in particular, avoidant and emotion-focussed strategies, which are particularly common when problems are perceived as threatening or harmful (Ptacek et al., 1992 in Frydenberg 1997). Some of the avoidant strategies utilised by participants were identified as escapism, which included denial, ignoring and pretending, and fatalism. For example:

"I do not expect to earn from the casino, but the reason I go there is because I want to escape or forget the problems happening to me."

"My son says he is not a gambler. He says he only goes to the casino when he has money and asks how his behaviour is defined as gambling."

"Our family is good at lying; we pretend to each other that things are going well for us all, so we don't have to worry about each other. I's hard because I feel like I have to pretend too!"

'Pretending' appeared to give many participants an illusion of coping with difficult situations. This is concerning, as evidence suggests that this form of suppression often creates more serious psychological problems due to the eventual emergence of consequences from emotional repression or isolation of feelings (Sprinthall \& Collins 1995). 
Family members, significant others, and problem gamblers were cognisant of the potential for gambling to cause conflict and inter-personal disruptions within the family, and frequently attributed their avoidance of the problem to being afraid to intervene, and/or fearing that any intervention will jeopardise their relationships:

"I'm too scared to talk to dad about his problem, scared that he won't admit to the problem and it'll seem like I'm accusing him and we might start arguing... I don't want to upset our relationship."

It is possible that the reluctance to address problematic issues within the family expressed above, may be exacerbated by the lack of extended family for many immigrant families that would mediate such problems. Some Asian people may also tend to avoid talking about these problems because they prefer to keep issues within the family, due to the shame associated with such behaviour:

"The problem gambling stays in the family, even the lying and the secrecy stays in the family."

Fatalism emerged as a coping strategy commonly utilised by Asian family members. Many evidently resigned themselves to fate and accepted the problem as part of their destiny. This can be attributed to the Asian concept of Karma; one of the major Asian philosophies that guides beliefs and behaviours (Burnard et al. 2006; Tse et al. 2007). Accordingly, some Asian participants stoically accepted gambling related problems and resigned themselves to 'living with them' as they believed it was their fate to do so:

"Although it was hard, I thought I had to keep the family and stay in the relationship...I sort of accepted that this is my fate. There may be something to be resolved or should happen now in relation to my previous life."

Dysfunctional coping with the issues associated with problem gambling was seen to result in a number of negative impacts and consequences for Asian families.

Negative impacts and consequences associated with problem gambling

Impacts and consequences commonly experienced by Asians in this study included: social disconnection and family conflict, financial insecurity, and mental health issues.

\section{Social disconnection and family conflict}

A tendency for social connections and relationships to suffer as addiction intensifies, has been acknowledged elsewhere (Adams 2008). Families of problem gamblers in this study reported that as individuals become more drawn into problem gambling, their relationships with others change and they appear to move towards isolating themselves from their friends and family and become antisocial and secretive:

"Gamblers lose interest in their families and friends... Gamblers usually don't have friends.... They become loners."

In some cases problem gambling had serious consequences on the 'sense of family' and sense of security that is usually a core feature of Asian families. 
"When my mother heavily gambled, my family was like, just as if the heart of the family stopped pumping, everything was frozen... The family wasn't really a family. It was just a collective of different individuals not touching each other."

Some problem gamblers had reportedly become aggressive. Some participants indicated that family members were often subject to violence, as problem gamblers attempted to exert some control over their lives and their families from whom they have become disconnected:

"When he wants money he can do anything. He has hit me so many times. He has been very abusive and later on he has said sorry. But at that time, he owes the money and if I don't give it to him he becomes absolutely wild."

This is in keeping with other research that has demonstrated a link between problem gambling and family conflict/violence (Korman et al. 2008; Tse 2007), with the Productivity Commission reporting that one in ten gamblers in counselling reported domestic or other violent incidents related to their gambling.

Violence caused by problem gambling often contributed to a breakdown of the family unit:

"When I got seriously depressed last year, I decided to divorce. I asked myself, why are you still with him?”

Furthermore, children were reportedly neglected and exposed to gambling early in life by parents who gambled:

"My biggest concern is the second generation really... Many parents gamble and have drinking problems, couple problems... The children are pretty much on their own here."

"They play games like mah-jong and the four year old holds the money because they're the only ones they can trust...so at a very young age they're already integrated into the gambling scene."

The socialisation of young children to gambling is important to consider, especially with regard to problematic gambling in parents, as a consistently identified risk factor for problem gambling amongst youth is parental problem gambling (Delfabbro et al. 2005; Dowling et al. 2010.

\section{Financial insecurity}

Problem gambling impacts the financial security of gamblers and their families, irrespective of their ethnicity. More significantly, for recent Asian immigrants, financial insecurity caused by problem gambling impacts on their ability to settle successfully in New Zealand by preventing them from purchasing or retaining a home, which is a key marker of settlement for them:

"If we go for their loan approval the bank will refuse it. [if they see] them go to the casino and withdraw money very often, they just refuse the loan approval."

"I used rent money and savings, I gambled to the stage where I lost my house." 
Financial insecurity has reportedly led some Asian problem gamblers to engage in other socially undesirable activities:

"She started gambling and now she has moved to prostitution. She was a nice girl, but now she is involved with the company of bad guys."

\section{Mental health issues}

All groups of participants reported several mental health issues, such as high levels of personal stress, anxiety, anger, unhappiness and depression with negative physical health consequences such as insomnia and illness:

"Because of his gambling, I was very stressed... At night I was not getting sleep, so my doctor prescribed me medications. I was on medication due to depression as well as for sleeplessness."

For problem gamblers, these mental health issues exacerbated their gambling:

"I became very anxious as I was getting more into the gambling. Maybe it's because I was worried about the money I lost, the money I borrowed... I was also scared that I might not be able to control myself forever. Then because I was so anxious, I needed to do something. Then I went to the casino or bar to gamble."

Major depression, substance abuse, relationship issues, unemployment, financial stress, and legal issues are known to be risk factors for suicide ideation and suicide (Maccallum \& Blaszczynski 2003). Several studies report such consequences for problem gamblers (Horodecki 1992; Statham et al. 1998; Weissman et al. 1999). Reports from participants in this study also highlighted these issues amongst Asian problem gamblers:

"[There are] Cambodians who killed themselves because of gambling. One of them killed himself on a railway track, and the other one hanged himself."

The results above show that problem gambling has devastating consequences for Asian immigrants, which impact on their ability to settle successfully into their new environment.

\section{Conclusion}

Gambling and problem gambling are complex matters impacted by culture and issues such as settlement into the New Zealand environment and the impact of the settlement experience on levels of resilience and ability to cope with adversity. As such, efforts to address problem gambling amongst Asian immigrants must consider the ecological context and aim to moderate those variables that contribute to problem gambling and enhance those that protect against it. The data suggest that resilience is an important factor in protecting against problem gambling, and that five key variables could enhance resilience amongst Asians. Figure 1 depicts the interactions and relationships between these variables. 


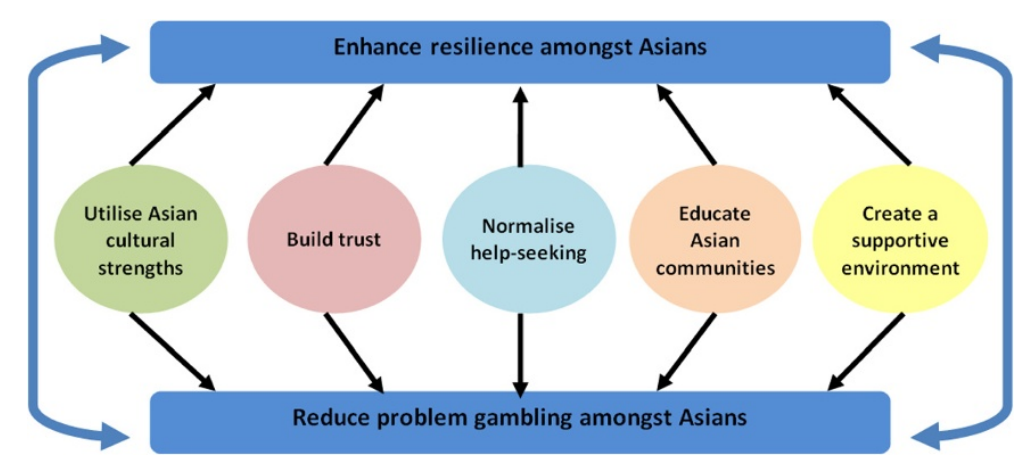

Figure 1 Interactions and relationships between key variables that may ameliorate problem gambling amongst Asian immigrants.

Enhancing and preserving the resilience that Asian immigrants bring with them emerged as a key factor in reducing and mediating the risks of problem gambling. The migration experience, if negative, can erode levels of resilience and impact immigrants' ability to cope functionally with settlement adversities and avoid addictive behaviours such as problem gambling. This research illustrates that Asian culture has numerous strengths that can be used to enhance resilience and protect against gambling. These strengths lie in values such as family connectedness and respect, spirituality and religion, the stigma attached to gambling, as well as the need to save face.

Building trust between Asian immigrants and hosts and host services emerged as an area needing attention. Asians are not accustomed to confidentiality in the public sector; consequently, they are hesitant to trust health or other services with confidential information. Ensuring that Asian communities have confidence in service providers is essential to successful intervention. Furthermore, seeking help for gambling related problems is not the norm for most Asians; hence, it is important to normalise talking about these problems and help-seeking behaviour. This can be done by reducing the stigma associated with problem gambling, changing perceptions of help-seeking and providing culturally appropriate services. Asian immigrant communities also appear to have limited knowledge about the dangers of gambling and need to be educated about these. There is a need to dispel misconceptions about gambling behaviours and to provide information on services.

Of utmost importance is creating a supportive social and institutional environment for Asian immigrants. This will assist with enhancing resilience and protecting against gambling behaviours. This may be achieved by providing social support including the provision of appropriate social spaces for interaction for Asian communities that are in the early stages of integrating into the New Zealand society, community support and opportunities for inter-ethnic interaction; enhancing family support through opportunities for reconstructing extended families; increasing support from Government and other agencies for influencing attitudes towards Asian immigrants, including garnering media support; and improving public health initiatives, including host responsibility measures.

Adopting an ecological approach such as this has the potential to reduce problem gambling in Asian communities. This research illustrates that gambling amongst Asians has to be understood within the wider social and institutional context in which Asians 
are located. As such, the responsibility of problem gambling amongst Asians in New Zealand does not only lie with the Asian population, but is an issue that requires the sincere attention of communities, NGOs, government agencies, and members of gambling industries.

\section{Competing interests}

The authors declare that they have no competing interests.

\section{Authors' contributions}

ASM designed the study, analysed and interpreted the data and contributed to the report writing. FVR contributed to the design of the study, analysis and interpretation of the data and report writing. ASKW gathered the data and contributed to analysis and interpretation of the data and report writing. All authors read and approve the final manuscript.

\section{Author details}

${ }^{1}$ Centre for Asian and Ethnic Minority Health Research, School of Population Health, University of Auckland, 261 Morrin Road, Glen Innes, Auckland 1072, New Zealand. ${ }^{2}$ Centre for Gambling Studies, School of Population Health, University of Auckland, 261 Morrin Road, Glen Innes, Auckland 1072, New Zealand.

Received: 21 February 2013 Accepted: 13 August 2013

Published: 19 August 2013

\section{References}

Abbott, MW, \& Volberg, RA (2000). Taking the pulse on gambling and problem gambling in New Zealand: Phase One of the 1999 National Prevalence Survey. Report number three of the New Zealand Gaming Survey. Department of Internal Affairs: Wellington.

Adams, PJ (2008). Fragmented Intimacy: Addiction in a Social World. New York: Springer Sciences.

Addison, JT (1992). Urie Bronfenbrenner. Human Ecology, 20(2), 16-20.

Aycan, Z \& Berry, JW (1996). Impact of employment-related experiences on immigrants' psychological well-being and adaptation to Canada. Canadian Journal of Behavioural Science, 28(3), 240-251.

Bar-Yosef, R (1968). Desocialisation and resocialisation: the adjustment process of immigrants. International Migration Review, 2, 27-42.

Beiser, M, \& Hou, F (2001). Language acquisition, unemployment and depressive disorder among Southeast Asian refugees: a 10-year study. Social Science \& Medicine, 53, 1321-1334.

Bell, K, Jarman, N, \& Lefebvre, T (2004). Migrant workers in Northern Ireland. Belfast: Institute for Conflict Research. Berk, LE (2000). Child Development (5th ed., pp. 23-38). Boston: Allyn and Bacon.

Berny, JW (2005). Acculturation: living successfully in two cultures. International Journal of Intercultural Relations, 9, 697-712.

Blaszczynski, A, \& McConaghy, N (1989). Anxiety and/or depression in the pathogenesis of addictive gambling. The International Journal of Addiction, 24, 337-350.

Blaszczynski, A, Huynh, S, Dumlao, VJ, \& Farrell, E (1998). Problem gambling within a Chinese-speaking community. Journal of Gambling Studies, 14(4), 359-380.

Bronfenbrenner, U (1979). The Ecology of Human Development: Experiments by Nature and Design. Cambridge, MA: Harvard University Press.

Burnard, P, Naiyapatana, W, \& Lloyd, G (2006). Views of mental illness and mental health care in Thailand: a report of an ethnographic study. Journal of Psychiatric and Mental Health Nursing, 13, 742-749.

Chang, S, Morris, C, \& Vokes, R (2006). Korean Migrant Families in Christchurch: Expectations and Experiences. Wellington, New Zealand: Families Commission.

Chinese Family Life Services of Metro Toronto. (1995). Working with gambling problems in the Chinese community. Toronto: Author.

Chung, RHG (2001). Gender, ethnicity, and acculturation in intergenerational conflict of Asian American college students. Cultural Diversity and Ethnic Minority Psychology, 7(4), 376-386.

Cultural Partners Australia Consortium. (2000). The impact of gaming on specific cultural groups. Victoria, Australia: Author.

Delfabbro, P, Lahn, J, \& Grabosky, P (2005). Further evidence concerning the prevalence of adolescent gambling and problem gambling in Australia: a study of the ACT. International Gambling Studies, 5(2), 209-228.

Dixon, R, Tse, S, Rossen, F, \& Sobrun-Maharaj, A (2010). Family resilience: the settlement experience for Asian immigrant families in New Zealand. Wellington: The Families Commission.

Dowling, N, Jackson, A, Thomas, S, \& Frydenberg, E (2010). Children at Risk of Developing Problem Gambling. Final Report. A Report to Gambling Research Australia in fulfilment of Tender 103/06. Melbourne: The Problem Gambling Research and Treatment Centre.

Dyal, J, \& Dyal, R (1981). Acculturation, stress and coping. International Journal of Intercultural Relations, 5(4), 301-328.

Eisenstadt, S (1954). The absorption of immigrants. London: Routledge \& Kegan Paul.

Endler, NS, \& Parker, JDA (1990). Multidimensional assessment of coping: a critical evaluation. Journal of Personality and Social Psychology, 58(5), 844-854.

Folkman, S, \& Lazarus, RS (1988). Ways of Coping Questionnaire Research edition. Palo Alto, CA: Consulting Psychologists Press.

Frydenberg, E (1997). Adolescent Coping: Theoretical and research perspectives. London and New York: Routledge.

Furnham, A, \& Bochner, S (1986). Culture shock: Psychological reactions to unfamiliar environments. London: Mathuen. 
Gambling Research Australia. (2011). International student gambling: The role of acculturation, gambling cognitions and social circumstances summary report: A mixed-methods investigation of international student gambling. State of Victoria: Gambling Research Australia, Department of Justice.

Henderson, A, Trlin, A, \& Watts, N (2001). Squandered skills? In R. Starrs \& Asian Nationalisms in an Age of Globalization (Eds.), The employment problems of skilled Chinese immigrants in New Zealand (pp. 106-123). Richmond, Surrey: Curzon Press (Japan Library).

Horodecki, I (1992). Treatment model of guidance center for gamblers and their relatives in Vienna, Austria. Journal of Gambling Studies, 8, 115-129.

Ivie, D, \& Garland, B (2011). Stress and burnout in policing: does military experience matter? Policing: An International Journal of Police Strategies \& Management, 34(1), 34-66.

Kibria, N (1993). Family tightrope: The changing lives of Vietnamese Americans. Princeton, NJ: Princeton University.

Korman, L, Collins, J, Dutton, D, Dhayananthan, B, Littman-Sharp, N, \& Skinner, W (2008). Problem gambling and intimate partner violence. Journal of Gambling Studies, 24, 13-23.

Leary, MR (1990). Responses to social exclusion: social anxiety, jealousy, loneliness, depression and low self-esteem. Journal of Social and Clinical Psychology, 221-229(2), 9.

Lee, RM, Su, J, \& Yoshida, E (2005). Coping with intergenerational family conflict among Asian American college students. Journal of Counseling Psychology, 52(3), 389-399.

Maccallum, F, \& Blaszczynski, A (2003). Pathological gambling and suicidality: an Analysis of severity and lethality. Suicide \& Life - Threatening Behavior, 33(1), 88-98.

Marshall, GN, Elliott, MN, \& Schell, TL (2009). Prevalence and correlates of liferime disordered gambling in Cambodian refugees residing in Long Beach, California. Journal of Immigrant Minority Health, 11(1), 35-40.

Ministry of Health. (2006). Asian Health Chart Book 2006. Wellington: Ministry of Health.

New Zealand Press Association (NZPA). (2008). Professional migrants face discrimination in NZ - study. Retrieved from http://www.nzherald.co.nz/nz/news/article.cfm?__id=1\&objectid=10502032.

News. (2009). Discrimination against Asians in New Zealand grows. National Story. Retrieved from http://www.3news.co. nz/Discrimination-against-Asians-in-New-Zealand-grows/tabid/423/articleID/92200/Defaultaspx.

Parackal, S, Ameratunga, S, Tin Tin, S, Wong, S, \& Denny, S (2011). Youth'07: The health and wellbeing of secondary school students in New Zealand: Results for Chinese, Indian and other Asian students. Auckland: The University of Auckland.

Patton, MQ (1990). Qualitative evaluation and research methods. Newbury Park, CA: SAGE.

Petry, NM, Armentano, C, Kuoch, T, Norinth, T, \& Smith, L (2003). Gambling participation and problems among South East Asian refugees to the United States. Psychiatric Services, 54, 1142-1148.

Raghunathan, R, \& Pham, MT (1999). All negative moods are not equal: motivational influences of anxiety and sadness on decision making. Organizational Behavior and Human Decision Processes, 79(1), 56-77.

Raylu, N, \& Oei, TPS (2004). Role of culture in gambling and problem gambling. Clinical Psychology Review, 23, $1087-1114$.

Rigby, K (1996). Bullying in schools: and what to do about it. Camberwell VIC: Australian Council for Educational Research.

Salant, T, \& Lauderdale, DS (2003). Measuring culture: a critical review of acculturation and health in Asian immigrant populations. Social science \& medicine, 57(1), 71.

Scragg, R (2010). Asian health in Aotearoa in 2006-2007: trends since 2002-2003 (p. 2010). Auckland: Northern DHB Support Agency.

Sobrun-Maharaj, A (2002). The social acceptance of visible ethnic minority adolescents of Asian origin in Auckland secondary schools. Auckalnd: Massey University.

Sobrun-Maharaj, A, Tse, S, Hoque, ME, \& Rossen, F (2009). The Settlement and Social Inclusion of Immigrant Youth in New Zealand. The International Journal of Interdisciplinary Social Sciences, 4(7), 97-112.

Sobrun-Maharaj, A., Rossen, F, \& Kim, S (2011). Work experiences of Asian immigrants: impact on family wellbeing. Wellington: The Families Commission.

Sprinthall, NA, \& Collins, WA (1995). Adolescent Psychology: A Developmental View. New York: McGraw-Hill, Inc.

Statham, D, Health, A, Madden, P, Bucholz, K, Bierut, L, Dinwiddie, S, et al. (1998). Suicidal behaviour: an epidemiological and genetic study. Psychological Medicine, 28, 839-855.

Statistics New Zealand. (2010). National Ethnic Populations Projections: 2006 (base) - 2026 update. Wellington: Statistics New Zealand.

Swick, K, \& Williams, R (2006). An analysis of Bronfenbrenner's bio-ecological perspective for early childhood educators: implications for working with families experiencing stress. Early Childhood Education Journal, 33(5), 371-378.

Tavares, H, Martins, SS, Lobo, DS, Silveira, C, Gentil, V, \& Hodgins, DC (2003). Factors at play in faster progression for female pathological gamblers: an explanatory analysis. Journal of Clinical Psychiatry, 64, 433-438.

Thomas, DR (2006). A general inductive approach for analyzing qualitative evaluation data. American Journal of Evaluation, 27(2), 237-246.

Tse, S (2007). Family violence in Asian communities, combining research and community development. Social Policy Journal of New Zealand, 31, 170-194.

Tse, S, Sobrun-Maharaj, A, \& Hoque, E.(2006). Research and Evaluation of Barriers to Asian People accessing Injury Related Services and Entitlements. Wellington, New Zealand: Centre for Asian Health Research and Evaluation, Auckland UniServices Limited, University of Auckland: Prepared for Accident Compensation Corporation.

Tse, S, Sobrun-Maharaj, A, \& Nayar, S (2007). Asian Mental Health Training and Development for Real Skills. Prepared for Te Pou, National Centre of Mental Health Research and Workforce Development. Auckland, New Zealand: The Centre for Asian \& Ethnic Minority Health Research, The University of Auckland.

Ward, C, \& Masgoret, AM (2007). Immigrant entry into the workforce: a research note from New Zealand. International Journal of Intercultural Relations, 37, 525-530. 
Weissman, MM, Bland, RC, Canino, GJ, Greenwald, S, Hwu, HG, Joyce, PR, et al. (1999). Prevalence of suicide ideation and suicide attempts in nine countries. Psychological Medicine, 29, 9-17.

Welte, JW, Barnes, GM, Wieczorek, WF, Tidwell, MO, \& Parker, JC (2004). Risk factors for pathological gambling. Addictive Behaviors, 29, 323-335.

Wong, J, \& Tse, S (2003). The face of Chinese migrants' gambling: A New Zealand perspective. eGambling: The Electronic Journal of Gambling Issues, 9, 1-11.

Yeh, CJ (2003). Age, acculturation, cultural adjustment, and mental health symptoms of Chinese, Korean, and Japanese immigrant youths. Cultural Diversity and Ethnic Minority Psychology, 9(1), 34-48.

Ying, Y-W, Coombs, M, \& Lee, PA (1999). Family intergenerational relationship of Asian American adolescents. Cultural Diversity and Ethnic Minority Psychology, 5(4), 350-363.

doi:10.1186/2195-3007-3-14

Cite this article as: Sobrun-Maharaj et al:: Negative impacts of gambling on Asian families and communities in New Zealand. Asian Journal of Gambling Issues and Public Health 2013 3:14.

Submit your manuscript to a SpringerOpen ${ }^{\circ}$ journal and benefit from:

- Convenient online submission

Rigorous peer review

- Immediate publication on acceptance

- Open access: articles freely available online

- High visibility within the field

Retaining the copyright to your article

Submit your next manuscript at $>$ springeropen.com 